\title{
A novel membrane bioreactor system for nitrification inhibition by cadmium
}

\author{
Omar Chaalal $^{1}$, Dalial Hank ${ }^{2}$, Ahmed M. Soliman ${ }^{3}$, Ahemd Embaby ${ }^{1}$, Farid Benyahya ${ }^{4}$ \\ ${ }^{1}$ U. A. E. University, College of Engineering, Al-Ain . U. A. E \\ ${ }^{2}$ National Polytechnic School, Environment Department, Algiers, Algeria \\ ${ }^{3}$ U. A. E. University, College of Science, Chemistry Department, Al-Ain, UAE \\ ${ }^{4}$ Qatar University, College of Engineering, Doha, Qatar
}

Email address:

chaalal@scientist.com (O. Chaalal)

\section{To cite this article:}

Omar Chaalal, Dalial Hank, Ahmed M. Soliman, Ahemd Embaby, Farid Benyahya. A Novel Membrane Bioreactor System for Nitrification Inhibition by Cadmium. International Journal of Environmental Monitoring and Analysis. Special Issue: Environmental Science and Treatment Technology. Vol. 2, No. 6-1, 2014, pp. 35-41. doi: 10.11648/j.ijema.s.2014020601.15

\begin{abstract}
The inhibitory effect of heavy metals in nitrification has not been extensively investigated although it is expected that some form of inhibition would show up in the presence of these. Since Cadmium is a common heavy metal present in industrial effluents, its effect on nitrification has yet to be evaluated in qualitative and quantitative terms. In this investigation, a novel approach to studying heavy metal inhibition and mitigation in a full nitrification regime has been adopted. This approach consisted of employing a two-compartment membrane bioreactor and conducting a series of nitrification experiments in the absence and presence of a natural adsorbent placed in either compartment. The results obtained thus far clearly indicated an inhibitory effect when both heavy metal and biomass were placed in the same compartment. Diffusive transport across the membrane of produced nitrite and heavy metal showed different characteristics: whilst nitrite evolved to the other compartment according to the concentration driving force, the heavy metal concentration in either compartment change little.
\end{abstract}

Keywords: Cadmium, Bioreactor, Fish Scales, Nitrification Inhibition

\section{Introduction}

The biological oxidation of ammonia in wastewater treatment processes is an important step in the overall treatment process because of the toxicity and other adverse effects of ammonia. However, it is very well documented that nitrification still remains a problematic issue in wastewater treatment because of the naturally slow growth of nitrifying bacteria associated in this process. Furthermore, the presence of heavy metals in wastewater streams exacerbates problems in nitrification since these tend to interfere with the biological oxidation steps in the form of activity or cell growth inhibition. Unfortunately, there is little data in the open literature on such important issues. Much of the papers published on this subject $[1,2,3]$ only refer to the potential of inhibition in nitrification by heavy metals. However, a recent study by Juliastuti et al [4] provided a useful insight into inhibition of nitrification by copper and zinc. Their study has provided threshold concentrations before inhibition became important, namely $0.05 \mathrm{mg} / \mathrm{L}$ for copper and $0.3 \mathrm{mg} / \mathrm{L}$ for zinc. Such limits can easily be encountered in most parts of the world in wastewaters. The threshold inhibitory limit of other and potentially more damaging heavy metals is yet to be determined. Furthermore, no solutions were offered in these studies to eliminate or reduce the effect of heavy metals on nitrification processes.

Clearly, there is an urgent need to investigate heavy metal inhibitory effects in nitrification processes, exploring a range of harmful heavy metals likely to be found in UAE wastewater streams. Novel, cheap heavy metal adsorbents should also be investigated to enable the removal of these heavy metals during wastewater treatment steps $[5,6]$. The prime difficulty a researcher would face in such circumstances is associated with the fact that it is difficult to study biological nitrification under heavy metal inhibitoryconditions and in the presence of adsorbent material. Indeed, there would be several interacting factors that would render interpretation of experimental findings extremely difficulty. The question one might ask is thus how can the heavy metal inhibitory effects in nitrification be 
studied and offer a solution to the problem at the same time.

The answer to this challenge probably lies in the technology adopted. One such technology that has been reported as promising in recent years is membrane bioreactors. It is a dynamic area in research as well as in large scale applications and therefore a great deal more work needs to be done in terms of generating experimental data for the purpose of developing high performance predictive and design models. Indeed, membranes have traditionally been employed in the area of separation technologies [7, 8, 9], but recently they were considered to have multiple functions by virtue of their potential in biological systems in particular when combined with other techniques like adsorption on natural products. One such natural product, namely fish scales, has been reported as promising but was not extensively tested $[10,11]$. Modeling of such multifunctional systems is virtually new and needs a great deal of attention. To begin with, extensive experimental data is required before any form of modeling exercise is initiated. Currently ,most models focus on transport phenomena involving molecular species and single or multi-component ionic species. Few models incorporate biological reactions and transport phenomena, presumably because of the scarcity of data on such systems.

It is therefore proposed to investigate the potential of a combined treatment method involving novel heavy metal adsorption on natural substance like fish scale in a specially configured membrane bioreactor and simultaneous biological oxidation of ammonia employing Nitrosomonas biomass. This approach has a dual benefit of providing information and data on heavy metal inhibition effects in nitrification and providing a basis for the modeling of combined adsorption and biological degradation of ammonia in wastewater using a purpose designed membrane bioreactor. This study is believed to be the first of its kind and therefore offers great potential for further studies.

\section{Experimental}

\subsection{Design of the Membrane Bioreactor}

The reactor designed for this investigation consisted of two compartments separated by a membrane in a $U$ shaped bubble column system arrangement [12]. The material of construction of the reactor was PVC. The bioreactor was aerated in both compartments by means of air sparging through nozzles on either side of the membrane. The air supplied was pressure regulated to about 1 atm and the flowrate controlled and measured by means of a flowmeter. The aeration has a dual function: supply of oxygen to the nitrifying biomass and membrane surface cleaning. Figure 1 depicts the novel membrane bioreactor and associated aeration system employed in this work. The height of each compartment tube was $50 \mathrm{~cm}$ and the diameter was $5.7 \mathrm{~cm}$. Each compartment can hold up to 2 liters of solution and can have (shown as compartment $\mathrm{A}$ or $\mathrm{B}$ in Figure 1) biomass and/or adsorbent. During the course of the investigation, small samples of solutions from both compartments could be collected for chemical analysis. The bioreactor was employed in batch mode with respect to the synthetic wastewater solution containing a source of ammonia, Cadmium salt, nitrifying cells and adsorbent.

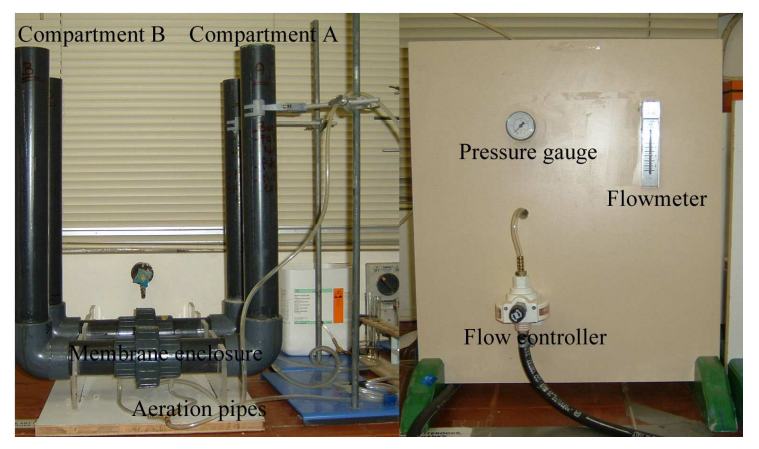

Fig 1. Membrane bioreactor system

\subsection{Design of Experiments}

Since this investigation is a novel approach towards the mitigation of nitrification inhibition by heavy metals (Cadmium in this case) and the outcome trends can be difficult to predict, a "scenarios approach" was adopted in the experimental design. In these scenarios, the content of the bioreactor compartments (A and B) was systematically changed for a specific experimental purpose. The various scenarios were termed systems 1 to 6 and are shown in Table 1 .

System 1 will act as a control to examine the nitrification efficiency, and the extent of transport of produced nitrite ions across the membrane. In system 2 , we will examine the effect of heavy metal on the nitrification process efficiency and in system 3, the effect of adsorbent will be examined and the extent of mitigating the inhibitory effects of the heavy metal studied. Finally, systems $5 \& 6$ concern the transport across the membrane and the adsorption rate of the heavy metal in two different configurations. It is clear that systems 1,5 and 6 are straightforward runs where only parameters like transport across the membrane, adsorption rate and nitrification efficiency will be measured. The other systems are however more complex and the interactions of the different constituents of each system become difficult to disentangle. For this reason, an expectations table was postulated to point at which experimental procedure should be adopted.

\subsection{Experimental Runs}

All experimental runs were executed in batch mode as previously indicated. Aeration was achieved through $1 \mathrm{~mm}$ glass nozzle connected to an air compressor, the air flow rate was kept at $8 \mathrm{~L} / \mathrm{min}$ maintaining a dissolved oxygen (DO) level of $7.3 \mathrm{mg} / \mathrm{l}$ during the whole run duration. The hydrophilic membrane material was nitrocellulose with a diameter of $90 \mathrm{~mm}$, pore size $0.22 \mu \mathrm{m}$ and thickness of 180 $\mu \mathrm{m}$. Stock solution of ammonium carbonate was prepared with a concentration of $70 \mathrm{ppm}$ as ammonia. Heavy metal concentration (Cadmium) was $50 \mathrm{ppm}$. The concentration of 
nitrifying bacterial slurry was $2 \mathrm{~g} / \mathrm{l}$ corresponding to $0.09 \mathrm{~g}$ dry biomass per liter.

Systems 1, 5 and 6 were independent runs since their results would not affect the scenarios of the other runs. However, systems 2, 3 and 4 were interdependent. That is why in this investigation these runs were done consecutively so that the result of the first one will lead us to the best scenarios to be adopted in the subsequent runs. In this investigation we started with system 2 , then 3 . System 4 was found to be unfeasible based on the results of system 2 .

Table 1. Various experimental scenarios employed

\begin{tabular}{|c|c|c|c|c|}
\hline & Constituent & Amount-unit & Compartment A & Compartment B \\
\hline \multirow{4}{*}{ System 1} & Ammonia (nh3) & $\mathrm{mg} / \mathrm{l}$ & $\mathrm{Xxx}$ & \\
\hline & Bacteria & G slurry-mg dry biomass & $\mathrm{Xxx}$ & \\
\hline & Heavy metal (cd) & $\mathrm{mg} / \mathrm{l}$ & & \\
\hline & Adsorbent & G & & \\
\hline \multirow{4}{*}{ System 2} & Ammonia (nh3) & $\mathrm{mg} / \mathrm{l}$ & $\mathrm{Xxx}$ & \\
\hline & Bacteria & G slurry-mg dry biomass & $\mathrm{Xxx}$ & \\
\hline & Heavy metal (cd) & $\mathrm{mg} / \mathrm{l}$ & $\mathrm{Xxx}$ & \\
\hline & Adsorbent & G & & \\
\hline \multirow{4}{*}{ System 3} & Ammonia (nh3) & $\mathrm{mg} / \mathrm{l}$ & $\mathrm{Xxx}$ & \\
\hline & Bacteria & G slurry-mg dry biomass & $\mathrm{Xxx}$ & \\
\hline & Heavy metal (cd) & $\mathrm{mg} / \mathrm{l}$ & $\mathrm{Xxx}$ & \\
\hline & Adsorbent & G & $\mathrm{Xxx}$ & \\
\hline \multirow{4}{*}{ System 4} & Ammonia (nh3) & $\mathrm{mg} / \mathrm{l}$ & $\mathrm{Xxx}$ & \\
\hline & Bacteria & G slurry-mg dry biomass & $\mathrm{Xxx}$ & \\
\hline & Heavy metal (cd) & $\mathrm{mg} / \mathrm{l}$ & $\mathrm{Xxx}$ & \\
\hline & Adsorbent & G & & $\mathrm{Xxx}$ \\
\hline \multirow{4}{*}{ System 5} & Ammonia (nh3) & $\mathrm{mg} / \mathrm{l}$ & & \\
\hline & Bacteria & G slurry-mg dry biomass & & \\
\hline & Heavy metal (cd) & $\mathrm{mg} / \mathrm{l}$ & $\mathrm{Xxx}$ & \\
\hline & Adsorbent & G & $\mathrm{Xxx}$ & \\
\hline \multirow{4}{*}{ System 6} & Ammonia (nh3) & $\mathrm{mg} / \mathrm{l}$ & & \\
\hline & Bacteria & $\mathrm{g}$ slurry-mg dry biomass & & \\
\hline & Heavy metal (cd) & $\mathrm{mg} / \mathrm{l}$ & $\mathrm{xxx}$ & \\
\hline & Adsorbent & $\mathrm{G}$ & & $\mathrm{Xxx}$ \\
\hline
\end{tabular}

$\mathrm{xxx}$ denotes the presence of the corresponding item

Table 2. Possible scenarios and expectations for system 3 and 4

\begin{tabular}{|c|c|c|}
\hline System number & Scenario of experiment & Expectations \\
\hline $\begin{array}{l}\text { System } 2 \\
\text { Bacteria }+\mathrm{NH}_{3}+\mathrm{HM} \\
\text { Cadmium }\end{array}$ & $\begin{array}{l}\text { A stock solution of ammonia ( } 70 \mathrm{ppm}) \text { will be placed } \\
\text { in compartment A + HM Cadmium ( } 50 \mathrm{ppm}) \text {, while } \\
\text { compartment B will contain same stock solution of } \\
\text { ammonia). } \\
\text { IF Bacteria is left to acclimatize to the new } \\
\text { environment for ( } 7 \text { days) then the heavy metal is } \\
\text { added } \\
\text { IF Bacteria and heavy metals are added from the start } \\
\text { of the run }\end{array}$ & $\begin{array}{l}\text { Nitrite liberation will be witnessed in the first days before addition of } \\
\text { the heavy metal (cadmium). Inhibition in a matter of } 12-24 \text { hours will } \\
\text { occur, recovery will be examined for next } 2-3 \text { weeks } \\
\text { There will be negligible nitrite liberation from the beginning of the run } \\
\text { and along the whole run duration, we will be examining the recovery } \\
\text { (if happening). }\end{array}$ \\
\hline $\begin{array}{l}\text { System } 3 \\
\text { Bacteria }+\mathrm{NH}_{3}+\mathrm{HM} \\
\text { Cadmium + Adsorbent }\end{array}$ & $\begin{array}{l}\text { A stock solution of ammonia (design concentration) } \\
\text { will be placed in compartment A + HM Cadmium + } \\
\text { adsorbent in the same compartment, while } \\
\text { compartment B will contain pure water. } \\
\text { IF Bacteria is left to acclimatize to the new } \\
\text { environment for ( } 5 \text { days) then the heavy metal is } \\
\text { added then the adsorbent later on } \\
\text { IF Bacteria and heavy metals are added since the } \\
\text { start of the run then the adsorbent is added later } \\
\text { IF Bacteria, heavy metals and adsorbent are added } \\
\text { from the start of the run }\end{array}$ & $\begin{array}{l}\text { Nitrite liberation at the first days of acclimatization, then inhibition on } \\
\text { addition of the heavy metal, addition of adsorbent later will not reverse } \\
\text { the inhibitory effects } \\
\text { Either adsorption/or/absorption of heavy metal on the bacterial cell } \\
\text { wall or penetrate inside the bacterial cytoplasm, the addition of } \\
\text { adsorbent later wont affect on the already adsorbed/absorbed heavy } \\
\text { metals ions } \\
\text { Occurrence of competition between the heavy metals ions, the bacterial } \\
\text { cells, and the nitrite ions on being adsorbed on the adsorbent surface. }\end{array}$ \\
\hline
\end{tabular}




\section{Results and Discussion}

\subsection{Optimum Adsorbent Dose}

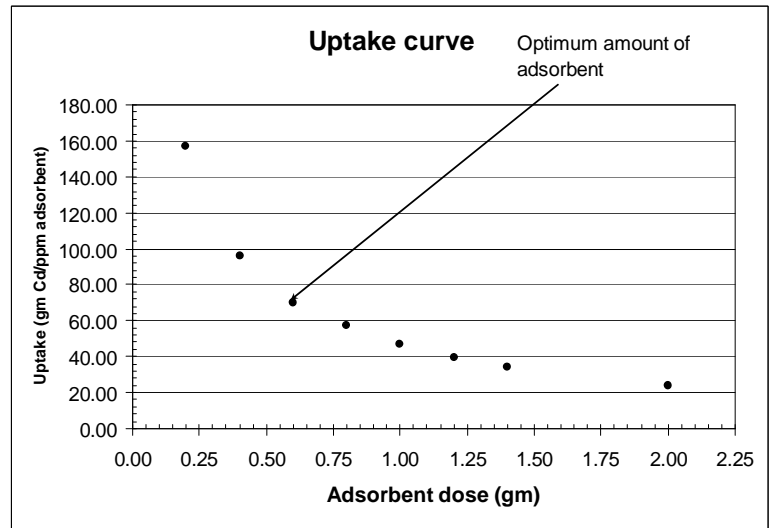

Fig 2. Adsorbent dose vs. uptake of Cd ions form solution

The optimum adsorbent dose was determined experimentally employing an initial Cadmium concentration of $50 \mathrm{ppm}$ and varying the amount of fish scale (without treatment) from 0.2 to $2 \mathrm{~g}$. Figure 2 indicates that $0.6 \mathrm{~g}$ is the optimum amount of fish scale adsorbent, and was thus employed in all experimental runs.

\subsection{Experimental Scenarios Analysis}

\subsubsection{System 5 \& 6 (Physical Phenomena)}

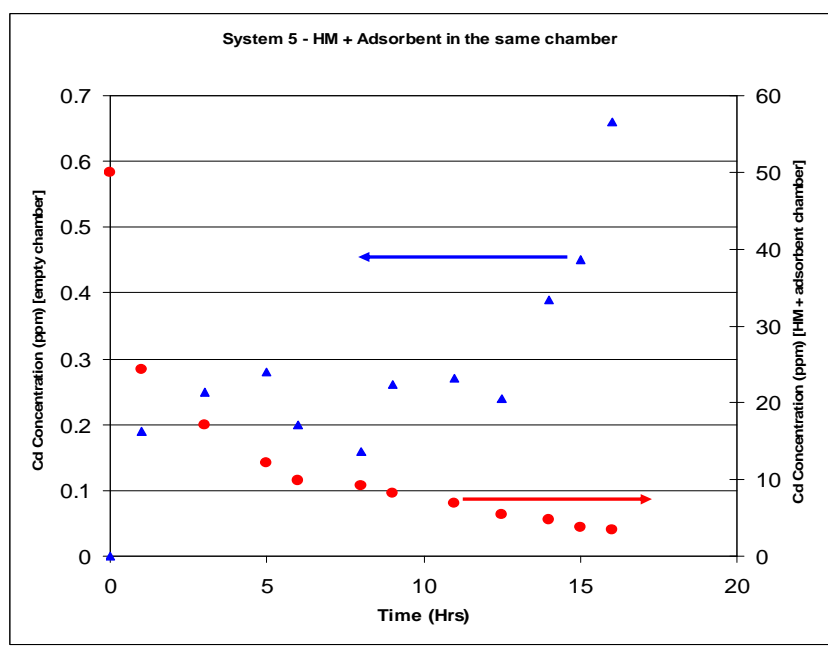

Fig 3. Cadmium ion concentration in compartments A and B (system 5)

As indicated in section 2, systems 5 and 6 represent experiments that determine the extent of heavy metal transport across the membrane as well as the adsorption rate of heavy metal onto fish scale. The formulations in Table 1 for these systems and the compartment configurations guided us in establishing that the transport rate of the heavy metal ion and the adsorption rate onto fish scale were very fast indeed. This can be easily deducted from Figures 3 and 4 . This leads us to the conclusion that fish scale has a high affinity for cadmium adsorption and that the size of cadmium ions does not represent a problem for the transport across the membrane depending on the concentration flux.

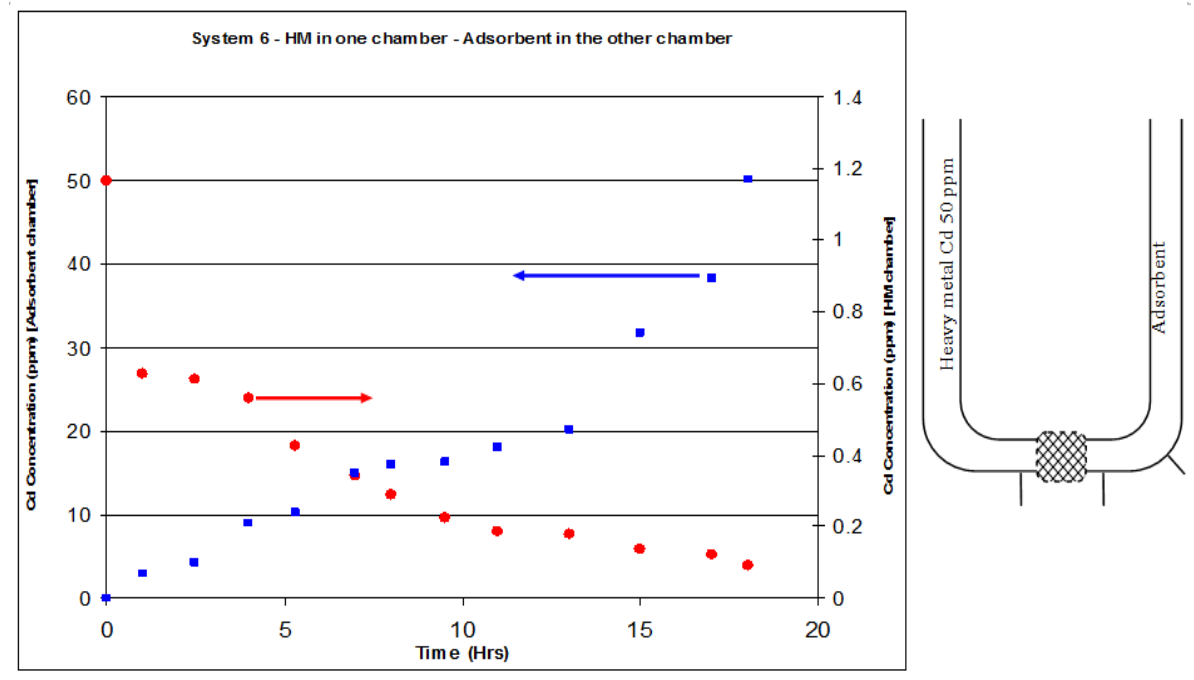

Fig 4. Cadmium ion concentration in solution in compartment A and B (system 6)

\subsubsection{System 2 (Biochemical and Physical Phenomena)}

In system 2, one chamber (compartment) of the membrane bioreactor contained the heavy metals and the nitrifying cells in the ammonia solution whilst the other chamber had only the ammonia stock solution (Table 2). Based on the scenarios listed in Table 2, there were two independent runs for system
2. In the first one (Scenario 1), the nitrifying biomass and the heavy metals were added from time $\mathrm{t}=0$ together, while in the second scenario (Scenario 2), the bacteria were added and left for some time to show its activity before the heavy metal $(\mathrm{Cd})$ was added to examine if activity recovery would take place or not. The results of these runs are shown in figures 5-8. 


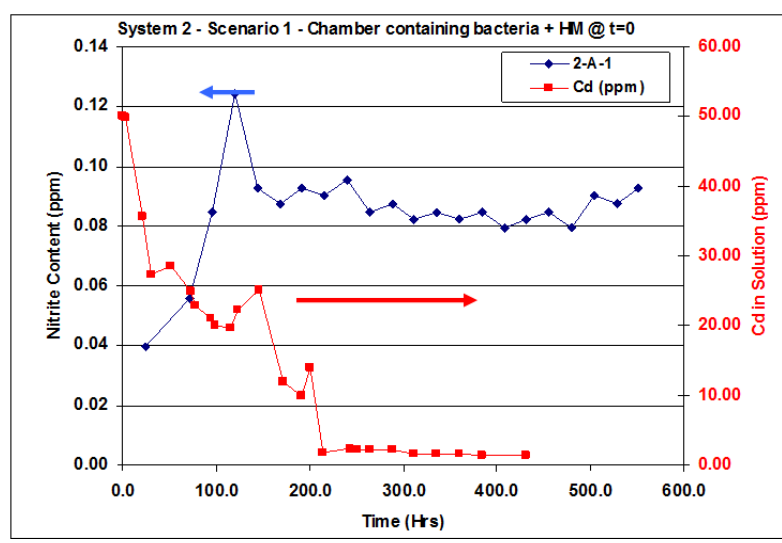

Fig 5. Cadmium ion \& nitrite concentration in solution (system 2-scenariolBacteria $+H M @ t=0)$

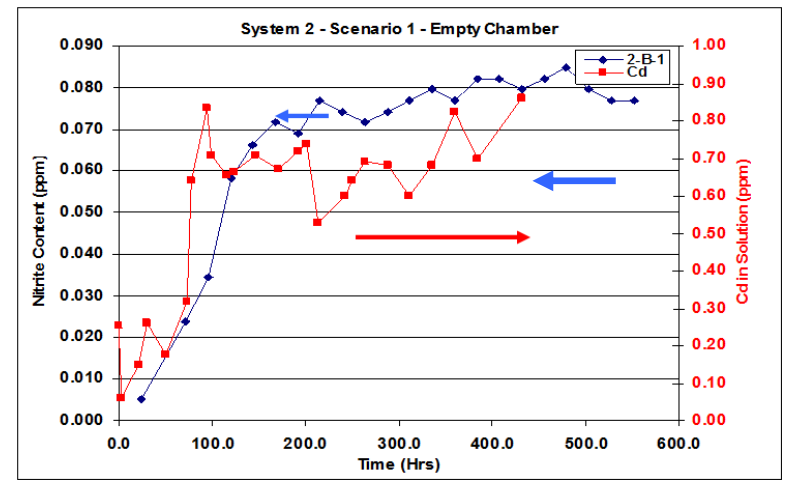

Fig 6. Cadmium ion \& nitrite concentration in solution (system 2-scenariolEmpty chamber)

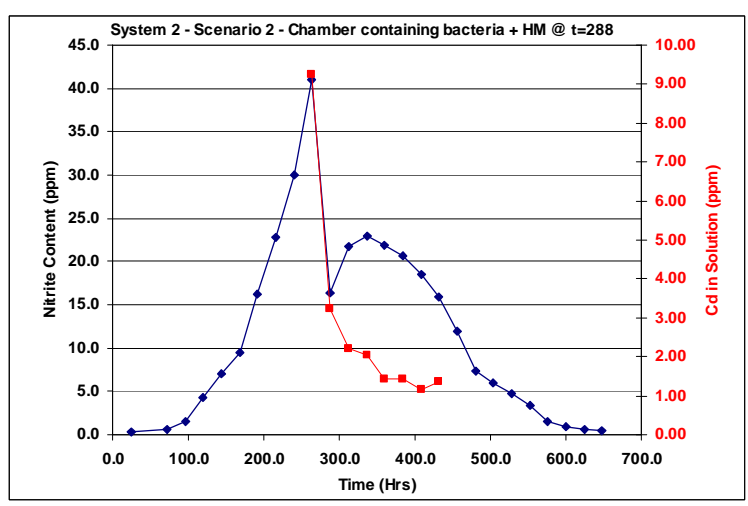

Fig 7. Cadmium ion \& nitrite concentration in solution (system 2-scenario2Bacteria $+H M @ t=288$ hrs $)$

From Figures 5-8, it is clearly shown that the nitrifying community was completely inhibited by the effect of the 50 ppm cadmium solution added from the start of the run in scenario 1. Almost no nitrite was produced and both chambers reached equilibrium for cadmium ions after 200 hours. However, an interesting observation was made: the disappearance of the cadmium ion from solution, suggesting that the inhibited suspended biomass acted as an adsorbent and gradually adsorbed the whole concentration of cadmium ions from the solution. Adsorption of heavy metals by biomass has been reported in the literature.

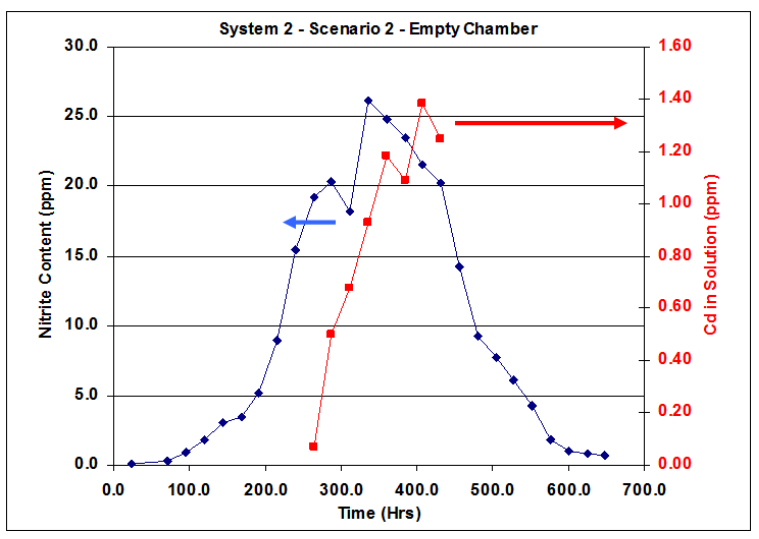

Fig 8. Cadmium ion \& nitrite concentration in solution (system 2-scenario2Empty chamber)

A similar trend was observed for scenario 2 as shown in Figures 7-8 where a highly active nitrifying biomass was left to reach its maximum activity for 12 days then the $50 \mathrm{ppm}$ cadmium solution was added. A complete halt of nitrite production occurred and disappearance of both nitrite and cadmium ions from the solution occurred similarly to what happened in scenario 1. This can be attributed to the same reason: the inhibited nitrifying biomass acted as a suspended adsorbent that adsorbed both the heavy metal and the nitrite ion produced earlier completely from the solution. This fact was confirmed by harvesting the biomass after the completion of the runs and washing it with $0.1 \% \mathrm{HCl}$ and doing a nitrite assay for the leachate which gave a highly positive nitrite presence. During the whole run, a very active transport phenomenon of nitrite radical was taking place in scenario 2 between both chambers depending on the concentration difference between both chambers.

\subsubsection{System 3 (Biochemical and Physical Phenomena)}

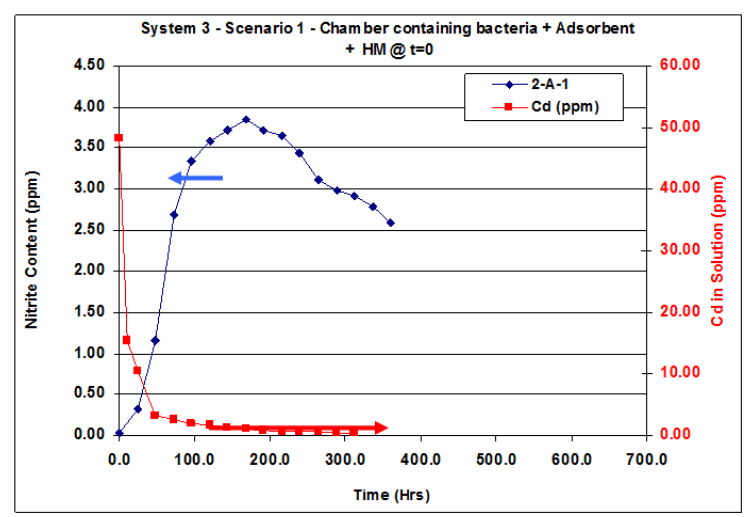

Fig 9. Cadmium ion \& nitrite concentration in solution (system 3-scenario1Bacteria + Adsorbent $+H M @ t=0)$

The trends in Figures 9-12 for system 3 are similar to those observed in system 2 . In scenario 1 , where the bacteria, heavy metal and the adsorbent were in the same compartment, negligible nitrite production occurred which confirms the complete inhibition of nitrifying biomass by the $50 \mathrm{ppm}$ cadmium ions concentration. No signs of recovery 
from this inhibition were noticed during 16 days from the start of the run.

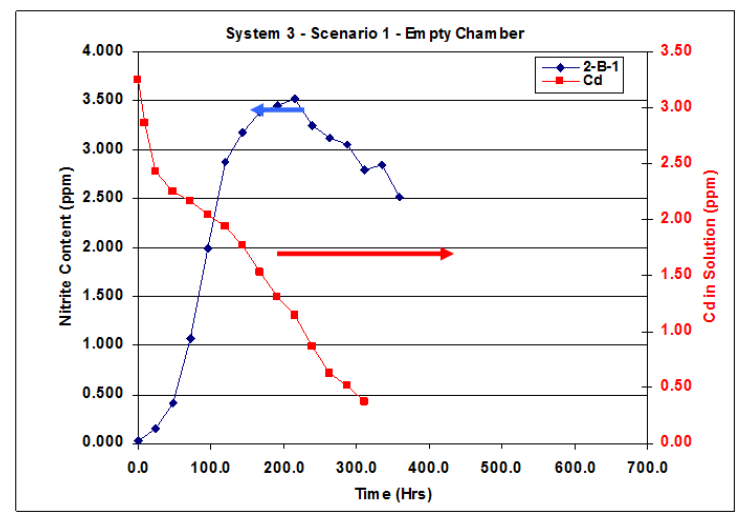

Fig 10. Cadmium ion \& nitrite concentration in solution (system 3scenario1- Empty chamber)

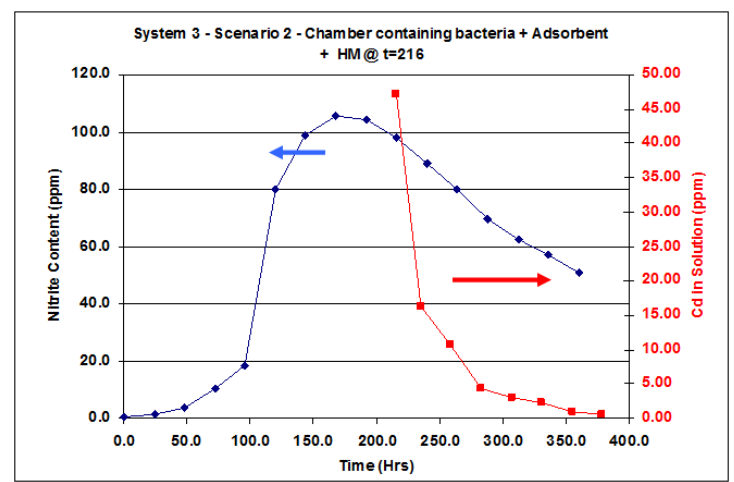

Fig 11. Cadmium ion \& nitrite concentration in solution (system 3-scenario 2-Bacteria + Adsorbent +HM@t=216 hrs)

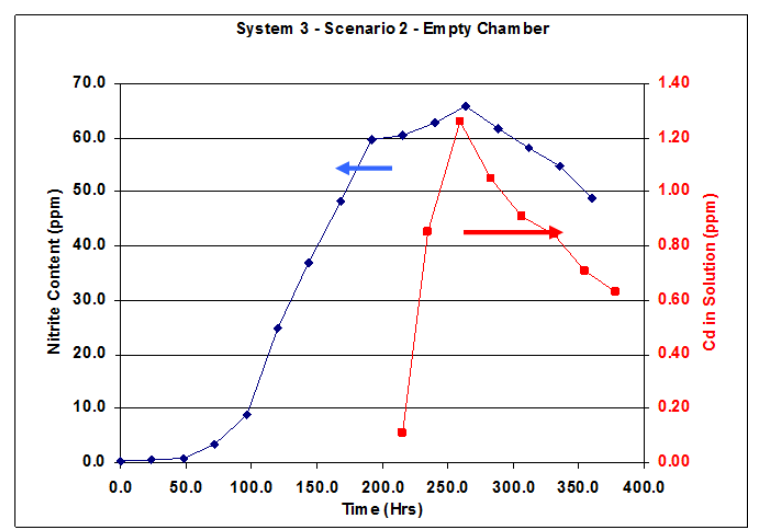

Fig 12. Cadmium ion \& nitrite concentration in solution (system 3-scenario 2- Empty chamber)

In scenario 2, it was deemed that the fish scale (adsorbent) would play a role as a natural potential biofilm carrier for the nitrifying biomass, hence protecting them from the heavy metal (cadmium) inhibitory effects, or acting as a preferable adsorbent material for the heavy metal (cadmium). The results has shown that the fish scale did not improve the situation, a very similar trend to what happened in scenario 2 in system 2 happened in system 3 .

\section{Conclusion}

The inhibitory effect of Cadmium on nitrification and its mitigation in a novel "two-compartment" membrane biochemical reactor in the presence of fish scale adsorbent have been investigated. It was found that nitrification reaction is very sensitive to Cadmium levels at around 50 ppm and that fish scale is an effective heavy metal adsorbent. The multiple scenarios adopted in the experimental design proved to be useful in explaining the various biochemical and physical phenomena observed in the reaction system. It was observed that inhibited biomass acted as an adsorbent for both heavy metal and nitrite produced from the biological oxidation of ammonia.

\section{Acknowledgements}

The lead author would like to acknowledge the financial support of the UAE University research sector to this work under grant 05-02-7-11/05 is also gratefully acknowledged.

\section{References}

[1] B Kartal, JG Kuenen, MCM Van Loosdrecht 'Sewage treatment with anammox'Science, Vol. 328 ( 2010)

[2] Afef Nasraoui-Hajaji, Houda Gouia1, Elisa Carrayol and Chiraz Haouari-Chaffei 'Ammonium Alleviates Redox State in Solanum Seedlings under Cadmium Stress Conditions' Journal of environmental and Analytical Toxicology. (2012)

[3] Shafkat A.B., Hassan M. and Chaudhary M.A.S., "Chromium (VI) inhibition in multi- substrate carbon oxidation and nitrification process in upflow packed bed biofilm reactor", Biochemical Engineering J., 1, pp 143-152 (1998).

[4] Jonsson, K., Grunditz K., Dalhammar K. and Jansen J.L.C., "Occurrence of nitrification in Swedish municipal wastewaters", Water Research, 34(9), pp2455-2462 (2000).

[5] Juliastuti, S.R., Baeyens, J., Creemers C., Bixio, D. and Lodewycks, E., "The inhibitory effects of heavy metals and organic compounds on the net maximum specific growth rate of autotrophic biomass in activated sludge", J. of Hazardous Materials B 100, pp 271-283 (2003).

[6] Kwang-Hyun Moon, Jae-Young Kim, Moon-Ik Chang, UnSung Kim, Seong-Jo Kim, Seung-Hwa Baek, 'Heavy Metal and Amino Acid Contents of Soybean by Application of Sewage and Industrial Sludge. 42 (2), 268 - 277. Journal of the Korean Society of Food Science and Nutrition, (2013).

[7] Staszak, K., Karaś, Z, and Jaworska, K 'Comparison of polymeric and ceramic membranes performance in the process of micellar enhanced ultrafiltration of cadmium(II) ions from aqueous solutions' Chemical Papers 67(4) 380-388 (2013).

[8] Adelung, S., Lohrengel, B. and Nghiem, L. Duc. 'Selective transport of Cadmium by PVC/Aliquat 336 polymer inclusion membranes (PIMs): the role of membrane composition and solution chemistry'. Membrane Water Treatment, 3 (2), 123131(2012) 
[9] 9. Z Liang, A Das, D Beerman, Z Hu 'Biomass characteristics of two types of submerged membrane bioreactors for nitrogen removal from wastewater' - Water research, (2010)

[10] Chaalal, O., Zekri, A. and Islam, R. 'Uptake of Heavy Metals by Microorganisms: An Experimental Approach' Energy Sources, 27:87-100, (2005).

[11] Basu, A: Mustafiz, S,Benjorndalen,N,; Chaalal, O. and Islam, $\mathrm{R}$ ' A Comprehensive Approach for Modeling Sorption Lead and Cobalt Ions through Fish Scales as an Adsorbent' Chemical Engineering Communications, Volume 193, Number 5, pp. 580- 236 605, (2006).

[12] Omar Chaalal , Abdulrazag Y. Zekri and Ahmed M. Soliman 'A novel technique for the removal of strontium from water using thermophilic bacteria in a membrane reactor' Journal of Industrial and Engineering Chemistry (2014). 